\title{
Change of Iranian EFL Teachers' Traditional Pedagogical Methods through Using Pronunciation Power Software in the Instruction of English Pronunciation
}

\author{
Abbas Pourhosein Gilakjani ${ }^{1} \&$ Narjes Banou Sabouri ${ }^{2}$ \\ ${ }^{1}$ Lahijan Branch, Islamic Azad University, Lahijan, Iran \\ 2 Department of Linguistics, Payame Noor University, Tehran, Iran \\ Correspondence: Abbas Pourhosein Gilakjani, 395, Opposite the Emam Hosein Mosque, Valiye Asr Street, \\ Rudsar, Guilan, Iran. Tel: 98-142-623-2762. E-mail: a_p_g48@yahoo.com
}

\author{
Received: November 11, 2013 Accepted: December 14, 2013 Online Published: January 5, 2014 \\ doi:10.5539/elt.v7n2p20 URL: http://dx.doi.org/10.5539/elt.v7n2p20
}

\begin{abstract}
The use of computer technology in learning and teaching has been studied by many studies but less research has been conducted for understanding users' feeling toward it and how this technology helps teachers develop their teaching methods. One of the computer technologies for the instruction of English pronunciation is Pronunciation Power software. This study examined the change of Iranian EFL teachers' traditional pedagogical methods in the use of Pronunciation Power software in teaching pronunciation. Qualitative method was used by the researchers. It involved semi-structured interview questions with a volunteer sample of four teachers from an open university in Iran. The researchers answered the research question related to the change of Iranian EFL teachers' traditional pedagogical methods toward using this software in teaching pronunciation. According to the findings obtained from the study, use of Pronunciation Power software by Iranian EFL teachers changed their traditional pedagogical methods. This change of teaching methods gave them more opportunities in the instruction of pronunciation.
\end{abstract}

Keywords: change, EFL teachers, pronunciation power software, pronunciation instruction

\section{Introduction}

Rajaduari (2001) stated that teachers can introduce pronunciation into their classes to strengthen the concepts that have been already taught in pronunciation classes, emphasize the concept of pronunciation as an important part of teaching English as a second/foreign language, provide opportunities for students to practice, and give high motivation to students to utilize it outside the classroom. According to Morley (1991), teachers should be pronunciation trainers and learners should be proactive learners who take the first step to learn it. Supra-segmental elements of pronunciation and communicative competence should be the basic aims of teachers' teaching not segmental elements of pronunciation and linguistic competence.

Some researchers said that one of the significant challenges that teachers encounter with changing education is to keep up with innovations. The effect of using computer technology on education in different fields has been investigated by these researchers. All of these researchers have emphasized the effectiveness of using computer technology in education and how it helps teachers improve their teaching methods and students' knowledge (Frigaard, 2002; Schofield \& Davidson, 2003; Timucin, 2006). According to Wernet, Olliges, and Delicath (2000), technology-enhanced education is one of the important parts of higher and professional education. When learners use computer technology, they can control their own learning process and can have access to a large amount of information over which teachers do not have any control. Teachers are the main agents of changes whose attitudes and beliefs support or prevent the success of any educational reform such as the use of computer technology.

Bitner and Bitner (2002) declared that teachers' beliefs, attitudes, perceptions, opinions, personality, and knowledge affect the choices they make about what, when, and how to teach through using computer technologies. Teachers can decide whether and how to use computer technology for instruction in the classrooms. Becker (2000) emphasized that fundamental changes in teaching methods require that teachers' teaching, methods, and technology should be completely examined. 


\subsection{Teachers' Pedagogical Methods}

The relationship between teachers' teaching methods and computer technology use is one of the other personal factors that should be specially considered. A study was done by Wozney, Venkatesh, and Abrami (2006) in Quebec, Canada towards the beliefs of 2,213 teachers in the implementation of computer technology. It was shown that teachers who liked more student-centered methods integrated computer technologies more than the teachers who preferred teacher-centered methods. According to Chen (2004) and Judson (2006), there isn't any relation between teachers' teaching styles and their computer technology use in the classrooms.

Computer technology changes teachers' teaching methods. Computer technology allows teachers to move from the role of dispenser of knowledge to a facilitator and permit them to persuade their students to become active learners. Teaching method must change from dispensing information to creating activities that engage students' minds and offer problems with numerous solutions (David, 1991). According to Becker (2000a) and Zhao and Cziko (2001), teacher's teaching methods affect their uses of computer technology. Previous research displayed that there are some teachers who can use well computer technology for their instruction (Sheingold \& Hadley, 1993).

Sheingold and Hadley (1993) described these teachers who can use computer technology in different ways. Changes in teachers' teaching methods present more intricate materials to their learners, permit learners to work more independently and become a guide and facilitator in their instruction. A study was done by Dexter, Anderson and Becker (1999) in the US. Forty seven teachers took part in this study. Based on the findings obtained from this study, it was exhibited that teachers who adopted more student-centered teaching methods did not believe that computer technology can change their teaching methods. Another study was done by Chen (2004). Taiwanese teachers supported student-centered method but they also used teacher-centered method. With respect to the different findings that are obtained from different countries, it is recommended that researchers do more research to be able to investigate the relationship between teachers' teaching beliefs, attitudes and computer technology use.

One of the results of computer technology training is teaching change in which teachers are engaged. Roblyer, Edwards, and Havriluk (1997) stated that teachers become more student-centered and less interested in whole-class instruction through using computer technology in their instruction. Their activities are more open-ended and students are urged to follow solutions and they emphasize cooperation and healthy competition. Dwyer, Ringstaff, and Sandholtz (1991) stated that computer technology changes teachings. These changes are to move teachers from the dispenser of knowledge to the facilitator of that knowledge, to provide more opportunity for individualized instruction and to spend less time lecturing to the whole class. By using computer technology, teacher-centered classes are moved to more student-centered strategies through which students look for information, analyze data and draw their own conclusions. This change in teaching method prevents the use of computer technology. But it can be removed by training and supporting teachers in the change process (Chapman, 1997).

\subsection{Role of Computer Technology in English Pronunciation Instruction}

According to Machovikov, Stolyarov, Chernov, Sinclair, and Machovikova (2002) and Najmi and Bernstein (1996), there are two aims in utilizing computers for teaching English pronunciation: (a) recognizing the student's mistakes in pronunciation and (b) helping them in correcting these mistakes. Neri, Cucchiarini, and Strik (2002) said that computer-assisted pronunciation instruction has numerous advantages that cannot be found in traditional teaching methods. These advantages are (a) students are provided with unlimited input through using digitized pronunciation software individually (b) individualized feedback can be provided to them automatically (c) many pre-recorded materials can be used by learners through using computers (d) high quality sound is one of the qualities of pronunciation software that gives learners the opportunity to look at articulatory movements used in producing sounds and (e) learners can compare their sounds to that of a native speaker.

Hismanoglu (2006) stated that Computer-Assisted Pronunciation Teaching (CAPT) provides a private and stress-free environment for students through which they can access to unlimited input, practice at their own pace, and receive feedback through the integration of automatic speech recognition. Computer Assisted Pronunciation Teaching provides learners with private and stress-free practice with individualized and immediate feedback on pronunciation. Many pronunciation teachers use Internet-based materials to teach pronunciation instead of using traditionally printed materials like course information, lecture notes, exercises, and quizzes (Neri, Cucchiarini, Strik, \& Boves, 2002). Hişmanoğlu (2010) emphasized that teachers can give pronunciation materials to students through the electronic means by changing the way in which students receive phonological input. 
According to Hişmanoğlu (2010), pronunciation teachers can apply colorful, natural, and interesting teaching materials into their lessons through using Internet-based materials because they offer minimal pairs, tongue twisters, songs, sound animations, step-by step phonetic descriptions, and video animations particular to segmental and supra-segmental aspects of English pronunciation. Hardison (2004) investigated the impact of computer-assisted prosody training and its generalization to segmental accuracy and lexical recall. Researcher did two experiments in this study. In the first experiment, the researcher used a real-time computerized pitch display in a 3-week training of French prosody training for some English speaking learners. He applied native French speakers' sentences as feedback to the subjects' initial production. Teachers rated subjects' pre - and post-test productions based on the prosody and segmental accuracy and improvements were determined in both areas. In the second experiment, the researcher tested a memory recall task and the results showed that the subjects' lexical memory became better through their prosodic memory built by the training. Pitch play was very useful to supra-segmental training and the positive effect of this training on segmental and lexical was identified.

Research findings support the impact of visual displays such as spectrograms. Coniam (2002) examined a method for sensitizing trainee English teachers from Hong Kong to supra-segmental phonological features in English. The authentic spoken material of both Hong Kong English and American English drawn from a local TV through spectrograms was analyzed by the researcher. The researcher wanted to display the difference between the syllable-timed Hong Kong English and stress-timed American. Teachers used spectrograms to understand the relationship between a staccato rhythm and the notions of stress and syllable timing. The subjects of this study were language teachers not learners. These teachers showed a different language knowledge background than language learners.

Neri, Cucchiarini, and Strik (2006a) studied a group of immigrants in the Netherlands. They were divided into three groups: regular instruction with supplemental instruction from an ASR-based Dutch CAPT system, a CAPT system without feedback, and no CAPT system. Students showed positive feedbacks to both the ASR-based CAPT systems and the CAPT system without ASR after the training. Largest segmental improvements belonged to the group with exposure to the ASR-based CAPT system and the group using CAPT system without ASR. Mich, Neri, and Giuliani (2006) tested the beliefs of many experts toward utilizing Computer-Assisted Language Learning (CALL) system based on ASR technology and on sound pedagogical guidelines. Young Italian students learning English were the subjects of this study. Experts compared a group of students receiving teacher-led instruction with a group receiving ASR-based CALL for individual word pronunciation. Both groups of students improved significantly their overall pronunciation quality of both general words and difficult/unknown words. It was concluded that the system was very effective in improving students' pronunciation.

\subsection{Features of Pronunciation Power Software}

Pronunciation Power software has been developed and distributed by English Computerized Learning Inc. This software is used by four thousand universities, colleges, businesses, and schools worldwide. It has two levels. The first level is beginning level (PP1) and the second one is intermediate to advanced level (PP2) (Pronunciation Power, 2000). Pronunciation Power 1 has over 7000 practice words and thousands of sentences, over 100 hours of training, over 2000 photos and graphics, animated lessons, 1020 listening exercises, hours of exercises for practicing stress, timing, articulation, intonation, and rhythm and four interactive, exciting new games (Pronunciation Power, 2000). Pronunciation Power 2 has all the features of PP1 and 52 sounds that are necessary for speaking clearly, ability to compare your sound to the sound of teachers, see how sounds are made by moving the animated side view of the mouth and the tongue, test your listening skill with 650 various sentence exercises, ability to practice pronunciation through interactive and exciting exercises involving 780 sample words and 1040 different sentences (Pronunciation Power, 2000).

\subsection{Application of Pronunciation Power Software}

This software has been designed to help learners learn the separate sounds of English language. This software provides exercises about phoneme, word and sentence levels and stress. Learners can hear sounds that are pronounced and then they can see the way of producing sounds. It has also speech analysis and learners can record their sounds and compare them with the pronunciation of their instructors. Learners can develop fluent speaking skills through the use of Pronunciation Power 1 and 2. New learners who have some basic knowledge in grammar and vocabulary can use Pronunciation Power 1. Pronunciation Power 2 provides more advanced practice with full sentence intonation and vocabulary. Pronunciation Power programs provide support up to learners' current level and to permit them to progress at their own pace (Pronunciation Power, 2000). It completes what learners are learning in class and help them increase their pronunciation learning. This program 
can be used by teachers in their classrooms to complete their pronunciation instruction. While learners are progressing on their own, this allows teachers to work with each student separately (Pronunciation Power, 2000).

\subsection{Statement of the Problem}

Hayati (2010) stated that one of the difficult skills for language users is English pronunciation and it is very important for them. It seems that both Iranian EFL university teachers and learners take no notice to it because there is no enough time for learning pronunciation and overcrowded classes make the situation even less favorable. There are serious problems for some Iranian EFL university teachers in both pronunciation teaching and learning. They are always challenging with the critical problems they face with English pronunciation in their EFL classrooms. Computer technology is one of the best means of improving and solving English pronunciation teaching and learning. It provides new opportunities for teachers and learners to engage in active communication that facilitates the process of teaching and learning English pronunciation. According to Fathiyan (2004), computers are used by Iranian EFL university teachers that are the replacement of tools of education such as blackboards, chalk, and overhead projectors because they provide them new and better means of educational methods and improve their pronunciation teaching and learning. This does not mean that they don't have any problems toward using computer technology or are able to use it well.

Although Computer-Assisted Pronunciation Teaching (CAPT) has much more advantages than traditional teaching methods, but some Iranian EFL university teachers use traditional teaching methods such as the audio-lingual method for their learners instead of using computer technology. These EFL university teachers rely too much on traditional teaching methods in textbooks without paying attention to their own students' problems (Hayati, 2010). First, most materials do not have any foundation in English pronunciation research findings. This stops teachers' understanding of the reasons for the content and suggested activities and therefore do not permit for correct matching to students' needs. Second, teachers who do not have a basis in either linguistics or English pronunciation research would not be able to make accurate decisions about the uses of computer software in English pronunciation instruction (Derwing \& Munro, 2009). The researchers investigated how the Iranian EFL university teachers' traditional pedagogical methods have changed through using Pronunciation Power software.

\subsection{Objective of the Study}

This study investigated how Iranian EFL university teachers' traditional pedagogical methods have changed through using Pronunciation Power software.

\subsection{Research Question}

This study answered the following research question:

How have the Iranian EFL university teachers' traditional pedagogical methods changed when Pronunciation Power software is used?

\section{Methodology}

\subsection{Research Design}

Researchers used a qualitative method design for this study. They interviewed a volunteer sample of four Iranian EFL university teachers. Qualitative method provided a clearer picture of the change of Iranian EFL teachers' traditional pedagogical methods about utilizing Pronunciation Power software in English pronunciation instruction.

\subsection{Population}

Researchers talked to four faculty members of the English Translation Department at the Islamic Azad University of Lahijan and got their agreement to take part in qualitative research. They voluntarily participated in the semi-structured interview sessions of data collection processes. Researchers used Iranian EFL university teachers' pseudonyms for this study not their real names. They were called P1, P2, P3, and P4.

\subsection{Research Instrument}

Researchers used semi-structured interview as an instrument for gathering data and investigating the aim of the study. They conducted semi-structured interview questions with four volunteer EFL teachers from the Lahijan University. They asked Iranian EFL teachers to gather qualitative data about the change of their traditional pedagogical methods through using Pronunciation Power software in pronunciation instruction. A high quality small size tape recorder was used by researchers to record interviews. Researchers tagged tapes for recording information at the beginning of each interview. After finishing each interview, they transcribed that interview. 
They did the coding of the data. Word-by-word transcription was used by researchers. They did a careful revision of transcription to make sure that the transcription matched the actual interview. After revising transcription, researchers interpreted interviews. Researchers revisited the interviewees to eliminate any potential of wrong interpretations of the interviews and shared with them some of the interpretations. They informed the interviewees at the first meetings that follow-up interviews might be needed.

\section{Data Analysis}

Researchers analyzed the semi-structured interview questions based on the qualitative data analysis procedures. Data analysis consists of reduction of collected data, theme construction or displaying the collected data, and theory building or drawing conclusions from the collected data (Miles \& Huberman, 1994). Miles and Huberman's suggestions were used by the researchers in analyzing the data. The collected data was reduced based on simplifying the data, selecting and focusing on the relevant data, and eliminating the irrelevant data. Researchers arranged data according to different themes and looked at the categories based on the change of teachers' traditional pedagogical methods. Then researchers drew conclusions. Each part of the interview had a theme that helped researchers to see the related data and to use quotations from the interviewees input to support arguments.

\subsection{Analysis of Research Question: How Have the Iranian EFL University Teachers' Traditional Pedagogical} Methods Changed When Pronunciation Power Software Is Used?

The use of Pronunciation Power software affected the quality of Iranian EFL teachers' pronunciation lessons. There was a change in the quality of Iranian EFL university teachers' pronunciation instruction through the change in the learners' competence in English pronunciation. Pronunciation Power software provided better solutions to traditional teaching methods in EFL teachers' native-like pronunciation, knowing how to use the correct intonation, comparing one's own pronunciation with native speakers' pronunciation, being enjoyable and attractive and offering interactive pronunciation learning environment. Iranian EFL teachers supported Pronunciation Power software and regarded traditional teaching methods as superficial and too old to be used. Important themes of the above question are shown in the following table.

Table 1. Important themes in change of Iranian EFL university teachers' traditional pedagogical methods about utilizing Pronunciation Power software

\begin{tabular}{ll}
\hline No. & Themes \\
\hline 1 & Quality of Teaching \\
2 & Traditional Teaching Methods vs. Pronunciation Power Software \\
\hline
\end{tabular}

Description: Results of the research question indicated that Iranian EFL teachers changed their traditional teaching methods through the use of Pronunciation Power software.

\subsection{Quality of Teaching}

Based on the interviews, Pronunciation Power software changed the quality of Iranian EFL teachers' instruction in English pronunciation lessons.

Well, I have used Pronunciation Power software to improve my teaching methods and to make my students understand the English language pronunciation and to make my students improve their level of English pronunciation in a shorter time.

The use of Pronunciation Power software has affected the quality of my English pronunciation lessons. There was a change in the quality of my instruction through the use of this software.

According to interviews, the Iranian EFL university teachers helped learners find pronunciation knowledge not to give them this knowledge. According to the researcher's observation, EFL learners found pronunciation knowledge and tried to depend on themselves not always on their teachers.

I am not the giver of pronunciation knowledge but the helper to find that knowledge. I expect the pronunciation knowledge my students are expected to know to be higher than dependence on me as the only source of pronunciation knowledge.

Pronunciation Power software has this potential to improve the way of my pronunciation instruction and to show faster results in my learners' English pronunciation knowledge. My learners themselves find pronunciation 
knowledge by means of this software.

Interviews demonstrated that effective English language pronunciation instruction depended on the change of Iranian EFL teachers' teaching methods.

I realized that my success in using Pronunciation Power software was bounded by my willingness to change my teaching methods. I helped my learners to get knowledge about pronunciation and wanted them not to be just dependent on me as the source of pronunciation.

P1

Pronunciation Power software certainly made an important change in my English pronunciation instruction. It was an essential part for effective teaching methods of English language pronunciation. I played the role of a guide and helper to my students to find pronunciation knowledge rather than giving them that knowledge. P2

I used Pronunciation Power software in my English pronunciation teaching because I wanted to have a change in my teaching method. Instead of telling everything about pronunciation to my students, I tried to help them find that knowledge.

The change in my pedagogical methods was not limited to changing the way of presenting materials but it is a change in terms of the effect on the students and also changing the students themselves to be ready to exercise more authority in their English pronunciation learning.

\subsection{Traditional Teaching Methods vs. Pronunciation Power Software}

Interviews exhibited that Pronunciation Power software provided native-like pronunciation, correct intonation and sensitivity to the incorrect pronunciation. According to the researcher's observation, Iranian EFL teachers gained near-native pronunciation and they were too sensitive to wrong pronunciation.

I support Pronunciation Power software because I got the native-like pronunciation and transferred it to my learners.

I used Pronunciation Power software in teaching English pronunciation because I could repeat and pronounce each word correctly and I was very sensitive to incorrect pronunciation.

Through using Pronunciation Power software, I knew how to use the correct intonation and I will be motivated to use this software for the other skills of pronunciation such as American accent, stress and rhythm.

Based on interviews, through using Pronunciation Power software, P3 and P4 could search and download programs and compare their pronunciation with native speakers' pronunciation. These were not possible through using traditional teaching methods.

I support Pronunciation Power software because a) I searched on the internet, b) I listened to CDs, and c) I downloaded programs from the net and it will in turn help them. I could not find these in traditional teaching methods.

Pronunciation Power software was used to compare my pronunciation with native speakers' pronunciation and I did not see traditional teaching methods important for this.

Interviewees such as P1 and P2 showed that Pronunciation Power software was better than traditional teaching methods because it provided native-like pronunciation and interactive learning environment.

I favor Pronunciation Power software because some skills like pronunciation cannot be taught through traditional teaching methods and native-like pronunciation can be obtained through using this software. Pl

Pronunciation Power software offered me interactive pronunciation learning environment. Through using this software I could see the English words, hear them and repeat them. As a result, I improved my pronunciation. P2

Changing traditional teaching methods to include Pronunciation Power software needed time which P3 liked to have more.

In my opinion, traditional teaching methods can be removed in teaching pronunciation provided that I have abundant time to use Pronunciation Power software.

Interviews indicated that training and preparation were important for the Iranian EFL university teachers like P1 and P2 to change their teaching methods through using Pronunciation Power software.

In my idea, training was an important factor in changing my teaching from using traditional methods to the use of this software in teaching English pronunciation.

In my belief, readiness and training were two significant factors that helped me to use Pronunciation Power software in teaching pronunciation and abandon traditional teaching methods. 
P3 and P4 said that traditional teaching methods were devoid of adequate activities and were superficial and unconnected to their pronunciation classes.

I can say that traditional teaching methods do not have sufficient materials for teaching pronunciation so this persuaded me to use Pronunciation Power software in the instruction of pronunciation.

In my opinion, traditional teaching methods are superficial and are not connected to my teaching needs in pronunciation. Therefore, I preferred using Pronunciation Power software in the instruction of English pronunciation.

\section{Discussion}

In the following section, research question related to the change of Iranian EFL university teachers' traditional pedagogical methods is discussed in detail.

4.1 Research Question: How Have the Iranian EFL University Teachers' Traditional Pedagogical Methods Changed When Pronunciation Power Software Is Used?

Pronunciation Power software changed Iranian EFL university teachers' teaching methods. This finding has been supported by David (1991). He said that teaching method must change from dispensing information to creating activities that engage students' minds and present intricate problems with many solutions. The above finding is also supported by Becker (2000a) and Zhao and Cziko (2001). They stated that teacher's pedagogical methods are very important in affecting teachers' uses of computer technology.

Pronunciation Power software training had an important impact on the change of Iranian EFL teachers' teaching methods. This finding is in consistent with the findings of Roblyer, Edwards, and Havriluk (1997). They said that pedagogical change is a direct outcome of any computer technology training in which teachers are engaged. They continued that through integrating computer technology into instruction, teachers become more student-centered and less interested in whole-class instruction. The above finding is also in accordance with the finding of Chapman (1997). He stated that through using computer technology, teacher-centered lectures are moved to more student-centered strategies in which students search for information, analyze data and draw their own conclusions. This change in teaching method sometimes causes a barrier in using computer technology. But it can be removed by training and supporting teachers in the change process.

Pronunciation Power software was used by the Iranian EFL university teachers in changing their teaching methods because it increased their learners' cooperation to each other and it also affected the quality of their English pronunciation lessons. The Iranian EFL university teachers were not the givers of pronunciation knowledge but the helpers to find that knowledge. This potential was seen in Pronunciation Power software that improved the way the English pronunciation was taught and showed faster results in teachers' pronunciation knowledge. Teachers' success in using Pronunciation Power software was bounded by their willingness to change their teaching methods. The above finding has been supported by Dwyer, Ringstaff, and Sandholtz (1991). They stated that computer technology changes teaching methods. These changes were moving teachers from the dispenser of knowledge to the facilitator of that knowledge, providing more opportunity for individualized instruction and spending less time lecturing to the whole class. The above finding is also similar to the study of Ely and Plomp (1986). They said that teachers will be less of an information-giver and more of a learning facilitator. Teachers are still the primary resource persons who serve as more of a manager than as a fountain of knowledge.

Pronunciation Power software provided better solutions for teaching pronunciation than traditional pedagogical methods. The Iranian EFL university teachers saw a considerable change in their English pronunciation. They said that change in their pedagogical methods was not limited to changing the way of presenting pronunciation materials but it was a change in terms of the effect on the learners to exercise more authority in their pronunciation learning. The above finding has been supported by the study of Dawson, Cavanaugh, and Ritzhaupt (2008). They said that the introduction of computer technology into the classroom environment brings a change in the way learners learn. Changes are done in a positive direction by creating a learning atmosphere centered around learners rather than teachers. This is because of the replacement of the traditional methods with the use of computers as learning tools.

To sum up, the Iranian EFL university teachers:

1) Changed the quality of their teaching methods.

2) Changed their teaching methods through training.

3) Found better solutions for teaching pronunciation than traditional teaching methods. 


\section{Conclusion}

This study explored the change of Iranian EFL university teachers' traditional pedagogical methods through utilizing Pronunciation Power software in English pronunciation instruction. The use of Pronunciation Power software helped the Iranian EFL university teachers of this study perceive pronunciation instruction differently in terms of changing the quality of teachers' preparation for classes. Training in Pronunciation Power software was very important in changing the Iranian EFL university teachers' teaching methods. Better solutions for pronunciation teaching methods were provided by Pronunciation Power software such as native-like pronunciation and comparing one's own pronunciation with native speakers' pronunciation. This software provided the teachers with individualized pronunciation learning and increased their access to more pronunciation materials that were not attainable through traditional pedagogical methods. The findings of this study helped Iranian EFL university teachers to change their traditional pedagogical methods in the instruction of pronunciation with American accent. The study and its results might also suggest better ways of training and equipping teachers with strategies, techniques, and approaches.

\section{Acknowledgements}

We thank Seyedeh Masoumeh Ahmadi, Alizadeh, and Babaee for their extensive and insightful discussions and comments on the paper.

\section{References}

Becker, H. J. (2000). The exemplary teacher' paper: How it arouses and how it changed its author's research program. Contemporary Issues in Technology and Teacher Education, 1(2), 1-9.

Becker, H. J. (2000a). Findings from the Teaching, Learning, and Computing Survey: Is Larry Cuban Right? Education Policy Analysis Archives, 8(51), 2-32.

Bitner, N., \& Bitner, J. (2002). Integrating Technology into the Classroom: Eight Keys to Success. Journal of Technology and Teacher Education, 10(1), 95-100.

Chapman, D. W. (1997). Improving instructional practice: The teacher's dilemma. In J. Lynch, C. Modgil, S. Modgil (Eds.), Innovations in delivering primary education, Volume 3 of the Education and Development: Tradition and Innovation series. London: Cassell Publishers.

Chen, C. (2004). Why do teachers not practice what they believe regarding technology integration? Journal of Educational Research, 102(1), 65-75. http://dx.doi.org/10.3200/JOER.102.1.65-75

Coniam, D. (2002). Perceptions of a multimedia syllabus-Making the demands of a performance test more accessible. System, 31, 55-70. http://dx.doi.org/10.1016/S0346-251X(02)00073-8

David, J. L. (1991). Restructuring and technology: Partners in change. Phi Delta Kappan, 73(1), 37-40, 78-82.

Dawson, K., Cavanaugh, C., \& Ritzhaupt, A. (2008). Florida's EETT Leveraging Laptops Initiative and its impact on teaching practices. University of North Carolina at Wilmington, 41(2), 143-159.

Derwing, T. M., \& Munro, M. J. (2009). Putting accent in its place: Rethinking obstacles to communication. Language Teaching, 42, 476-490. http://dx.doi.org/10.1017/S026144480800551X

Dexter, S. L., Anderson, R. E., \& Becker, H. J. (1999). Teachers' views of computers as catalysts for changes in their teaching practice. Journal of Research on Computing in Education, 31, 221-238.

Dwyer, D., Ringstaff, C., \& Sandholtz, J. (1991). Changes in teachers' beliefs and practices in technology-rich classrooms. Educational Leadership, 48(8), 45-52.

Ely, D., \& Plomp, T. (1986). The promises of educational technology: A reassessment. International Review of Education, 32, 231-250. http://dx.doi.org/10.1007/BF02426060

Fathiyan, M. (2004). The study of a desired pattern of computer literacy for Iranian teachers. The University of Science and Industry, The Ministry of Education, The Design and Develop and Application Office of Information and Communication Technology.

Frigaard, A. (2002). Does the computer lab improve student performance on vocabulary, grammar, and listening comprehension? ERIC Document Reproduction Service. No. ED476749.

Hardison, D. (2004). Generalization of computer-assisted prosody training: Quantitative and qualitative findings. Language Learning and Technology, 8(1), 34-52.

Hayati, A. M. (2010). Notes on Teaching English Pronunciation to EFL Learners: A Case of Iranian High School Students. English Language Teaching, 3(4), 121-126. 
Hişmanoğlu, M. (2006). Current Perspectives on Pronunciation Learning and Teaching. Journal of Language and Linguistic Studies, 2(1).

Hişmanoğlu, M. (2010). Online Pronunciation Resources: Hobbies or Fobbies of EFL Teachers? IJONTE, 1(2), 40-53.

Judson, E. (2006). How teachers integrate technology and their beliefs about learning: Is there a connection? Journal of Technology and Teacher Education, 14(3), 581-597.

Machovikov, A., Stolyarov, K., Chernov, M., Sinclair I., \& Machovikova, I. (2002). Computer-based training system for Russian word pronunciation. Computer Assisted Language Learning, 15(2), 201-214. http://dx.doi.org/10.1076/call.15.2.201.8192

Mich, O., Neri, A., \& Giuliani, D. (2006). The effectiveness of a computer assisted pronunciation training system for young foreign language learners. Proceedings of CALL, 135-143.

Miles, M. B., \& Huberman, A. M. (1994). Qualitative data analysis: A sourcebook of new methods. Thousand Oaks, CA: Sage Publications.

Morley, J. (1991). The pronunciation component in teaching English to speakers of other languages. TESOL Quarterly, 25(1), 51-74.

Najmi, A., \& Bernstein, J. (1996). Speech recognition in a system for teaching Japanese. Journal of the Acoustical Society of America, 100(4). http://dx.doi.org/10.1121/1.416187

Neri, A., Cucchiarini, C., \& Strik, H. (2002). Feedback in computer assisted pronunciation training: When technology meets pedagogy. Proceedings of CALL Conference "CALL professionals and the future of CALL research", Antwerp, Belgium, (pp. 179-188).

Neri, A., Cucchiarini, C., \& Strik, H. (2006a). Selecting segmental errors in L2 Dutch for optimal pronunciation training. International Review of Applied Linguistics, 44, 357-404.

Neri, A., Cucchiarini, C., Strik, H., \& Boves, L. (2002). The Pedagogy-Technology interface in Computer Assisted Pronunciation Training. Computer Assisted Language Learning, 15(5), 441-467. http://dx.doi.org/10.1076/call.15.5.441.13473

Pronunciation Power. (2000). English Computerized Learning Inc., Edmonton. Publication Inc.

Rajadurai, J. (2001). An Investigation of the Effectiveness of Teaching Pronunciation to Malaysian TESOL Students. Forum, 39(3), 10-15.

Roblyer, M. D., Edwards, J., \& Havriluk, M. A. (1997). Integrating educational technology into teaching. Upper Saddle River, NJ: Merrill.

Schofield, J. W., \& Davidson, A. L. (2003). The impact of internet use on relationship between teachers and students. Mind, Culture, and Activity, 10(1), 62-79. http://dx.doi.org/10.1207/S15327884MCA1001_06

Sheingold, K., \& Hadley, M. (1993). Commonalities and distinctive patterns in teachers' integration of computers. American journal of education, 101(3), 261-315. http://dx.doi.org/10.1086/444044

Timucin, M. (2006). Implementing CALL in the EFL context. ELT Journal, 60(3), 262-271. http://dx.doi.org/10.1093/elt/ccl006

Wernet, S., Olliges, R., \& Delicath, T. (2000). Post course evaluation of Web CT (Web Course Tools) classes by social work students. Research on Social Work Practice, 10(4), 487-504.

Wozney, L., Venkatesh, V., \& Abrami, P. C. (2006). Implementing computer technologies: Teachers' perceptions and practices. Journal of Technology and Teacher Education, 14(1), 173-207.

Zhao, Y., \& Cziko, G. A. (2001). Teacher adoption of technology: A perceptual control theory perspective. Journal of Technology and Teacher Education, 9(1), 5-30.

\section{Appendix}

Semi-Structured Interview Questions

The following questions aim at covering the quality of Iranian EFL teachers' teaching and the comparison of traditional teaching methods with Pronunciation Power software.

Questions:

1. How has Pronunciation Power software improved the quality of your English pronunciation lessons? 
2. Could you describe how Pronunciation Power software has improved your pedagogical teaching methods?

3. Can you think of some examples where Pronunciation Power software has provided a better solution to traditional teaching methods?

\section{Copyrights}

Copyright for this article is retained by the author(s), with first publication rights granted to the journal.

This is an open-access article distributed under the terms and conditions of the Creative Commons Attribution license (http://creativecommons.org/licenses/by/3.0/). 